\title{
Exploring methods and practicalities of conducting sector-wide energy consumption accounting in the tourism industry
}

\author{
Authors \\ Jan Warnken* ${ }^{*}$, Melanie Bradley* and Chris Guilding† \\ * School of Environmental and Applied Science \\ Griffith University, Gold Coast Campus \\ † School of Accounting \& Finance \\ Griffith University, Gold Coast Campus \\ Correspondence address: \\ School of Environmental and Applied Science \\ Griffith University, Gold Coast \\ PMB 50 Gold Coast Mail Centre \\ Qld 9726, Australia
}

PHONE: 61755 948587, FAX 61755948067

Email: j.warnken@mailbox.gu.edu.au

- Author to whom correspondence should be addressed 


\title{
Exploring methods and practicalities of conducting sector-wide energy consumption accounting in the tourism industry
}

\begin{abstract}
Sector-wide environmental accounting is an important mechanism for reducing resource consumption and the production of waste output. However, to date, little attention has been paid to the practicalities of conducting sector-wide environmental accounting in fragmented, service-oriented industry sectors that comprise a diversity of small to medium-sized enterprises. This study explores such practicalities through a series of independent energy audits conducted in the Australian tourist accommodation industry. Three distinct energy consumption audit techniques are reviewed in the light of findings made from 35 energy audits, and more than 200 telephone and face-to-face interviews held with various accommodation sector representatives. The three sector-wide energy consumption accounting methods reviewed are: the Floor Area Method, the Multiple Regression Method and the Mandatory Reporting Method.
\end{abstract}

In light of different business structures, different in-house environmental accounting practices, and other major factors affecting resource consumption, mandatory reporting is found to be the most efficient and effective method. To facilitate its use, it is recommended that:

a) governments consider requiring resource consumption or waste production figures to be made generally accessible,

b) businesses are required to collect energy consumption data over several years in order to calculate relatively accurate models that capture the factors driving energy consumption, and

c) standardised accounting spreadsheets are developed to facilitate data collection for different types of enterprises.

Key words

Energy, audit, tourism, accommodation, mandatory reporting. 


\section{Exploring methods and practicalities of conducting sector-wide energy consumption accounting in the tourism industry}

\section{Introduction}

Global environmental issues such as climate change, decreasing water resources, increasing waste production and waste disposal, have moved to the forefront of social consciousness, political agendas and policy development (WCED, 1987; Ehrlich and Ehrlich, 1990; Hamblin, 1991; McMichael, 1993; Odum, 1998). In light of this development, environmental accounting appears to be attracting increasing attention (Epstein and Roy, 1997; Guilding and Kirman, 1998; Schaltegger and Burritt, 2000). It appears likely that Governments will come under increasing pressure to monitor environmental performance on an industrial sector basis, regardless of whether international agreements such as the Kyoto Protocol are ratified.

Environmental accounting and associated tools such as energy, water and waste audits, represent key approaches to measuring and monitoring environmental performance (Buckley, 1991; Ding and Pigram, 1995; Goodall, 1995; Marsden, 1996; Diamantis and Westlake, 1997). These tools were first developed for individual businesses in United States' manufacturing industries, as a response to government legislative requirements instituted in the late 1970s (Diamantis and Westlake, 1997). The use of environmental accounting is now becoming more widespread following the development of the ISO 14000 series by the International Organization for Standardization, and the European Union's Eco-Management and Audit Scheme (EMAS) (Bhat, 1998). However, ISO accreditation and the EMAS are voluntary, and implementation has tended to be restricted to large individual businesses within mining, manufacturing or service industries. Consequently, developing and operating environmental accounting for entire industry sectors is by no means straightforward. This is particularly the case for fragmented and diverse industries that typically comprise a high 
proportion of small to medium-sized business entities. Unfortunately, industry fragmentation represents a significant challenge in terms of achieving coherent and coordinated monitoring of sector-wide environmental performance. In particular, fragmentation signifies difficulty in developing environmental management systems that are appropriate for, and accepted by, a relatively diverse set of business operations.

A prime example of a fragmented industrial sector is the tourism industry, which comprises a large number of relatively heterogeneous small to medium sized business entities. Tourism is a significant sector which has recently been described as having emerged as the world's largest industry (Fennell, 1999). Accommodation provision, which is a major component of the industry, typifies the industry's fragmentation. In Australia, the accommodation sector encompasses international hotel and motel chains, independently owned and/or operated motels, self-contained apartment complexes owned through strata-title (condominiums), caravan parks, lodges, backpacker hostels and bed and breakfast operations (Australian Bureau of Statistics, 1997).

Given the sheer number of small to medium sized businesses within this sector, their combined environmental impact is potentially considerable. This is particularly the case when we recognise the "mind-set” of many tourists. Many tourists tend to view their vacation experience as a time for some indulgence. When vacationing, tourists are likely to behave in ways less consistent with environmental conservation, because the normal economic motivations for exercising resource consumption restraint are not apparent when renting most forms of tourist accommodation. ${ }^{1}$ In light of these factors, the tourism industry appears to be a particularly appropriate sector for an environmental impact analysis.

As the tourism industry encompasses a large number of small-scale accommodation providers, in the context of an environmental audit of the sector, it is vital that all types of operations are assessed, regardless of size. Sector-wide environmental accounting can 
facilitate: a) calculation of primary environmental costs during cost-benefit analyses, b) estimation of cumulative impacts for an activity or set of activities at a local or regional scale, and c) identification of priority areas for resource and environmental management. Ultimately, sector-wide assessment of environmental impacts will help governments determine if they are meeting their obligations as signatories to international agreements such as the Kyoto Protocol.

The over-riding objective of this study was to explore the practicality of applying sectorwide energy consumption accounting in the tourism industry. This exploration was conducted by initially reviewing three approaches that might be taken to sector-wide energy consumption accounting. These three approaches are: the floor area method, the multiple regression model method, and the mandatory reporting method. Following this review, a field study was undertaken to:

a) Review the incidence, nature and potential of energy consumption accounting.

b) Compile data to facilitate the development of individual business level regression models concerned with energy consumption prediction.

While the prime focus of the field study concerned the development of a data set that would facilitate an appraisal of the regression model method, observations allowing a commentary on the other two methods were also made. By analysing business management structures, current levels of in-house energy consumption accounting, and factors that influence energy consumption, recommendations are made for improving data collection and analysis for tourist accommodation and, to some extent, for other service industries. Indeed, if an environmental accounting method can be developed for the accommodation industry, it is likely to have ramifications for other fragmented industries, such as the retail and transport sectors. The study's originality derives from its focus on the tourism industry. Most prior

\footnotetext{
${ }^{1}$ In most forms of tourist accommodation, the tourist pays a flat rate, regardless of the extent they soil linen, consume electricity and water, etc.
} 
environmental accounting research has focused on less fragmented, non-service sectors such as mining and manufacturing (for example, Halloran et al., 1994; Saxena and Modepalle, 1994; Szwilski and Begley, 1998).

The remainder of the paper is structured as follows. The next section provides a discussion of the three approaches to sector-wide energy consumption accounting noted above. The field study research method adopted is then described. Subsequent sections address the findings relating to the incidence and nature of energy consumption accounting and the results of developing energy consumption regression models for those accommodation businesses that provided the requisite information. In light of findings made, the paper concludes with further discussion of the three energy consumption methods and a recommendation as to which appears to offer greatest promise for the tourism accommodation sector.

\section{Sector-wide energy consumption accounting: Three methods reviewed}

Sector-wide accounting is reliant on a central organization or agency to collect and process data from a range of individual businesses. In the case of Australian accommodation providers, this service is provided by the Australian Bureau of Statistics (ABS). The ABS conducts regular tourist accommodation surveys for different geographical areas within each Australian state and territory. These surveys are divided into four accommodation categories: 1) hotels, motels and guesthouses, 2) holiday flats, units and houses, 3) caravan parks, and 4) visitor hostels. The survey data include information such as number of businesses operating in each accommodation category, number of guest night and unit nights sold, and accommodation takings (ABS, 1997). This data base represents a resource that can be drawn upon as part of an environmental accounting system. A fundamental issue for accommodation providers is the performance of building management and design, and researchers from different disciplines have developed several methods to estimate the environmental 
performance of a set of building structures used for similar purposes. Three of the resulting, and probably most disparate, methods discussed will now be elaborated upon.

\section{The Floor Area Method}

The general aim of this approach is to calculate average energy consumption levels per unit of floor area for each business category. Deng and Burnett (2000), for example, used an energy use index that was based on site energy consumption per unit of gross floor area, for sixteen hotels in Hong Kong. On a larger scale, Mortimer et al. (1999) employed a similar measure to develop a database of energy use in the UK non-domestic building stock. More recently, Becken et al. (in press) calculated "energy intensity”, or energy use per square metre of floor area, for five types of accommodation in New Zealand.

The Floor Area Method involves the following:

1) Collect figures for annual energy consumption and total floor area from a representative sub-sample of businesses within each accommodation group or category.

2) Calculate average annual values for energy consumption per unit of floor area, for each group or category.

3) Multiply the average values by the number of businesses classified under each accommodation group or category, to obtain estimated total energy consumption values for each accommodation category.

4) Sum the values calculated for different categories of accommodation, to establish a sector wide value for energy consumption. Convert the sector-wide energy consumption value into greenhouse gas emissions using appropriate conversion rates.

\section{The Multiple Regression Method}

This approach involves developing a multiple regression model that predicts total annual energy consumption and subsequently, greenhouse gas emissions. Saxena and Modepalle 
(1994) developed such a model to predict electricity usage by companies within the printing industry. They chose four independent variables for their model: floor area area, number of employees, operating hours and annual sales, and found this method to be a relatively strong predictor of electricity consumption. Other benefits Saxena and Modepalle (1994) claimed for their model included its minimal data requirements and ease of use.

The Multiple Regression Method certainly minimises difficulties associated with subsampling and conducting energy audits for a range of individual businesses. This approach requires a sample of businesses to supply energy figures during the model's development phase. In terms of the accommodation sector, the steps for estimating energy consumption and greenhouse gas emissions are:

1) Develop multiple regression models for different categories of accommodation. These models should establish the relationship between energy consumption as the dependent variable, and relevant independent variables that affect energy use. Data for the dependent variable are obtained by surveying a representative sub-sample of businesses from each accommodation category. Data for the independent variables can be collected from sources such as a central statistics agency, weather stations and economic performance surveys. Generally, such models can be described by the following equation:

$$
\hat{E}_{i}=a+b_{1} x+b_{2} y+b_{3} z+\ldots
$$

where: $\hat{E}_{i}=$ mean figure for total annual energy consumption (MJ/year), for a particular accommodation category, $\mathrm{x}, \mathrm{y}, \mathrm{z}$ = independent factors deemed important, added or omitted as 
appropriate, e.g., mean annual temperature, mean annual occupancy rate, number of rooms, etc.

2) Once models have been developed, they can be used as the basis for estimating levels of energy consumption for each accommodation category. Values for the independent factors will need to be collected from the same sources that provided data initially (e.g. economic performance surveys and weather stations).

3) Calculate sector-wide energy consumption and greenhouse gas emissions as per step 4 of the Floor Area Method.

\section{Mandatory Reporting Method}

This method involves enacting legislation requiring individual accommodation providers to record their energy consumption levels. This information is then submitted to a central statistics agency along with other information such as number of guest nights/room nights, accommodation takings, and descriptive characteristics that allow businesses to be classified according to a particular accommodation category. Once submitted to the central agency, the data can be compiled. Analysis of the data collected would enable estimates to be made of annual energy consumption, and even energy consumption per guest/room night sold. The data could also be analysed by accommodation category, or the entire accommodation sector. Further, they could be converted into greenhouse gas emissions using appropriate conversion rates.

The idea of mandatory environmental auditing has been around for more than twenty years. It was first introduced in United States chemical and steel industries in the late 1970s (Goodall, 1995; Diamantis and Westlake, 1997; Sinclair-Desgagne and Gabel, 1997). More recently, Goodall (1995) suggested that in-house environmental auditing is likely to become a 
mainstream activity in the near future, with legislation making it mandatory for a range of economic sectors.

Irrespective of which of these three methods is used, the data generally required from businesses comprise measures of annual energy consumption and descriptive characteristics that allow accommodation category classification. As will be noted below, procurement of this data depends on two key factors: the willingness of businesses to cooperate with data collection, and the ability of the business to accurately monitor the requisite data.

\section{The field study research method}

A major task in the study concerned securing access to field data. Contact was made with eighteen hotels, twenty motels, and one hundred and six people connected with more than 30 condominiums, sixteen eco-resorts and ten caravan parks in the Gold Coast, Sunshine Coast and Cairns regions of Australia (see Table 1). These regions can be characterised as typical examples of relatively young, rapidly growing coastal tourism destinations. In terms of industry representation, it should be noted that the $A B S$ records statistics for n hotels, $\mathrm{m}$ motels, $\mathrm{x}$ condominium complexes, y eco-resorts and z caravan parks in these three tourist regions. [JAN, CAN YOU FILL IN THE MISSING NUMBERS HERE PLEASE].

From these contacts, sufficient data enabling a regression analysis to be conducted of energy consumption was provided by eleven hotels, zero motels, thirteen condominiums, five eco-resorts and one caravan park. In most cases, businesses were reluctant to participate in this study, despite a promise to provide feedback in the form of an individual business level energy consumption analysis benchmarked to sector-wide figures. This reluctance was particularly evident in motels, as owner/operators frequently cited time and resource constraints preventing their participation in the study. In several cases, concern over information confidentiality was cited as a reason for non-participation. No privately owned 
caravan parks were willing to participate in the study. A willingness to participate was found, however for a group of caravan parks owned by a local government.

Considerable variation in the quantity and quality of data provided was found for those businesses willing to participate in the study. ${ }^{2}$ Major inconsistencies encountered included:

- Energy consumption was recorded using a range of measurement units, e.g., kWh for electricity; and L, $\mathrm{m}^{3}$, Mcal or MJ for gas.

- Data for equivalent time periods could not be collected from every business. Some enterprises provided figures for a number of years, while others provided figures for twelve months or less.

These inconsistencies were the result of different business management structures as well as different levels of interest in in-house environmental accounting.

\section{Observations concerning the incidence and nature of energy consumption accounting}

Figures $1 \mathrm{a}$ and $1 \mathrm{~b}$ illustrate typical management structures for hotels, eco-resorts and condominiums. [JAN CAN YOU SWITCH FIGURES 1A AND 1B AROUND, IN LINE WITH THE REVIEWER'S REQUEST] The management structure for motels and caravan parks are not depicted because they tend to adopt relatively simple owner-operator structures. It should be noted that the caravan parks that participated in the study were atypical. General administration and marketing responsibilities were contracted to a specialist company contracted by the local council. Day-to-day operations and customer service on the other hand, were the responsibility of resident managers.

Table 2 provides an overview of the in-house energy auditing undertaken by the survey sample. In-house energy auditing for hotels is possibly driven by two major factors: 1) desire to manage operating costs and profit, and 2) marketplace standing. Firstly, the high levels of

\footnotetext{
${ }^{2}$ Due to their relatively large size, data appeared to be more accessible in large hotels.
} 
service and amenities expected by hotel guests signify that expenditure on energy and water consumption constitute major budgetary items (Aulbach, 1988). As a result, large hotels can be expected to monitor energy and water consumption as a budget line item. In this study it was found that energy consumption monitoring was usually undertaken by the engineering/maintenance department, often directed by senior hotel management or the parent hotel chain.

Secondly, in terms of marketplace standing, hotels often have strong brand names and associated reputations to uphold. In order to maintain their position in the competitive tourist accommodation market, it is important they are seen to be operating with a corporate conscience that demonstrates a sense of environmental responsibility. It is noteworthy that all hotels participating in the study kept relatively accurate energy consumption records (Table 2) and could provide data suitable for analysis (Table 1$).^{3}$

Generally, the eco-resorts were found to have a management structure similar to the hotel archetypal management structure (Figure 1a). It is to be expected that demonstration of a high environmental responsibility would be particularly important for this type of accommodation provider. However, it was found that operation under the eco-resort label did not always translate into good environmental practice management. While it was found that the Gold Coast eco-resorts placed emphasis on monitoring and reducing detrimental environmental impacts, the Cairns eco-resorts were concerned with promoting and providing a nature-based accommodation experience, rather than monitoring the environmental impact of their business. Discussions with managers at these resorts suggested that resource consumption monitoring was motivated more by a concern for minimising operating costs, than a concern for environmental issues. Furthermore, as indicated in Table 1, not all eco-resorts willing to participate in this study were able to provide data sufficient to facilitate a resource use audit.

\footnotetext{
${ }^{3}$ It should be noted, however, that this data may reflect a degree of self-selection bias, i.e., it could well be that hotels that declined to participate in the study tended to have relatively poor energy consumption accounting systems.
} 
It was found that motels contacted tended to be small, family owned and operated enterprises, where a single person assumed management responsibility. This responsibility encompasses administration, engineering and maintenance, and customer service. The workload associated with this undertaking appeared to prohibit the application of any monitoring initiatives over and above what is required for daily operations. As a consequence, none of the motels contacted could provide suitable energy consumption data.

As already noted, the caravan parks represented in the study were owned by a local government authority. It appeared that as these parks carried the local council's name, it was important that they are seen to be run efficiently and effectively. In light of this, the maintenance of accurate records in order to provide appropriate accountability for operations was a key component of the parks' management. It was found that the parks' central management company kept energy consumption records for each park, and did not have any objections to releasing figures.

Of the five types of tourism accommodation investigated, condominiums have the most complex management and ownership structure. As can be seen in Figure 1b, many different parties have a stake in condominium development, ownership and management. A condominium's principal management body, the body corporate, is prevented by law from making a profit. ${ }^{4}$ Where owners do not occupy their apartments, operating costs can be indirectly subsidized as tax deductible expenses. The diffusion of management and ownership responsibilities and the distinct financial provisions applying to condominiums signify that it is unlikely that all parties will hold an interest in improving environmental performance. These factors appear to limit adoption of environmental management procedures in condominiums. ${ }^{5}$ In fact, none of the condominiums surveyed maintained a record of energy consumption. As a result, conduct of the research required the sourcing of kWh figures from

\footnotetext{
${ }^{4}$ The Body Corporate Community Management Act 1997 (Qld).
} 
the condominiums' energy bills. This exercise was complicated by the deregulated status of the energy market in Queensland which has resulted in the emergence of different options for electricity purchase (Figure 2). Indeed, the different electricity purchasing arrangements made by the condominiums signified that the data collection methods used and the quantity of data collected varied across the condominiums investigated.

Obtaining condominium energy consumption data was problematical because it could be collected from a variety of sources: body corporate service providers, individual apartment owners, or resident building managers. Where electricity was purchased through the contestable consumption market, the body corporate service provider made bulk purchases of electricity on behalf of an entire condominium (Figure 2). Accordingly, they could provide total electricity consumption figures for both common property areas and individual apartments. However, for those condominiums that accommodated both holiday-makers and permanent residents, total energy consumption figures from the contestable market did not permit the determination of accurate values for tourist-related energy consumption.

In the case of condominium complexes that purchased electricity on a tariff basis from the local network distributor, only figures for common property consumption could be collected from the body corporate service provider. Details of electricity consumption in individual units had to be sourced from either the apartment owners or resident building managers (in some cases the resident building managers paid accounts on behalf of unit owners). In several cases it was not possible to obtain electricity consumption data for an entire complex, only for those units where the owner permitted the release of figures.

It has been found that there is a diverse range of management structures and in-house accounting procedures within the accommodation sector. These factors determine the ease with which independent energy consumption accounting can be undertaken. Where electronic

\footnotetext{
${ }^{5}$ Different owners and different resident managers will have different views on the importance of environmental protection. As a result, the promotion of environmental management procedures to be applied to a whole condominium complex is likely to be a challenging undertaking.
} 
record-keeping is used, energy figures can be supplied with relative ease. However, it has been found that, data sets from different businesses often cover different time periods, use different measures and in some cases, are incomplete.

\section{Operationalising the regression model method}

As indicated earlier, Saxena and Modepalle (1994) considered floor area area, number of employees, operating hours and annual sales, to be factors affecting energy consumption in printing companies. Factors considered in the context of accommodation include the attitudes and commitment of staff towards environmental management, environmental awareness of guests, number of guest rooms, the provision of extra services and facilities, hotel class, occupancy levels and total floor area (UK CEED, 1998; Deng and Burnett, 2000; Becken et al., in press).

In this study, emphasis was placed on factors that (a) could not be controlled by individual businesses, (b) are likely to affect environmental performance as measured on a per capita basis, and (c) could vary significantly between years. Interviews with hotel engineers, resident managers and caravan park supervisors revealed that occupancy levels, air temperature and relative humidity were parameters considered to have a significant effect on day to day operations. Accordingly, the independent factors chosen for regression analyses in this study were monthly occupancy levels, mean monthly relative humidity at three o'clock in the afternoon and mean monthly air temperature. Initially, the number of rain days were also considered for analysis, however it was decided not to include this factor because its main effect in tropical and subtropical climates, a significant decrease in air temperature, was already taken into account. Electricity and gas were the dependent factors analysed because they are the main sources of energy used by Queensland accommodation providers.

Figures for air temperature and relative humidity were provided by the Australian Bureau of Meteorology weather station closest to the study regions. Occupancy figures were collected 
directly from the accommodation providers. These three independent variables were continuous and therefore suitable for statistical analysis. In most cases, this data was readily available. As noted above, figures for electricity and gas consumption were, in most cases, collected directly from the accommodation providers.

The results of conducting a regression analysis for each tourist accommodation provider based on the three independent variables and using electricity and gas consumption as two separate dependent variables are reported in Table $3 .^{6}$ It can be seen that mean monthly relative humidity was not a significant factor in any of the regression models. ${ }^{7}$ On the other hand, monthly occupancy levels had a significant effect on monthly electricity consumption in 6 out of 20 analyses conducted. This effect was only found for hotels that are relatively compact in design (Table 3). In these buildings, guest rooms account for a large proportion of total building area. This signifies that electricity requirements for common use areas represent a relatively small proportion of total electricity consumption. This finding is intuitively appealing as a high proportion of hotel area dedicated to accommodation (low common area area) signifies a stronger relationship between electricity consumption and occupancy levels.

With respect to the eco-resorts examined, it has been found that those with both cabin and campground accommodation did not exhibit a relationship between electricity consumption and mean monthly occupancy levels. It is likely that campground guests will consume less energy than cabin guests and consequently, total levels of electricity use will be dependent on the number of guests staying in each type of accommodation, rather than the total number of guests per se. On the other hand, for Gold Coast Eco-resort 2, there was a strong positive

\footnotetext{
${ }^{6}$ At this exploratory phase of appraising different approaches to energy consumption accounting in the tourism accommodation sector, it was believed greatest insight derives from reviewing the practicality of developing regression models at the individual business level, rather than at the industry sector level. If it is not possible to develop valid regression models at the individual business unit level, it will obviously not be possible to develop sector-wide models due to cross-business differences in factors such as building configuration, level of services provided, wall insulation specifications, etc.

${ }^{7}$ It should be noted that a problem with the mean measure used is that in a month that has an equal proportion of very high and very low humidity days, the average humidity is "relatively normal". This disguises the fact that energy consumption might be high as a result of the incidence of high humidity days. The same problem can be seen to arise with the "mean monthly air temperature" used.
} 
relationship found between occupancy levels and electricity consumption. In this particular resort, management was able to isolate energy supply to those areas of the complex where guests were staying. This feature appears to have strengthened the occupancy/energy consumption relationship.

Regression analyses for condominiums were complicated by the manner in which energy consumption figures had to be collected. This resulted in regression analyses being undertaken for only two of the condominiums that supplied data. A positive relationship between occupancy and electricity consumption was not found for Gold Coast condominium 3, which bulk-purchased electricity. This result was understandable, given that within this particular condominium a high proportion of the units were occupied by permanent residents, whose occupancy had to be recorded as full-time despite the units sometimes being vacant. On the other hand, a strong relationship between occupancy and electricity consumption was evident for Gold Coast condominium 5, where access was granted to electricity accounts for each individual unit. In this complex units were separately metered, with hot water and air conditioning generated individually for each unit. Accordingly, energy consumption is highly related to occupancy rates, even though recording intervals spanned three months. In light of the 525 observations made, and the fact that these units contained a relatively standard set of equipment for Queensland self-contained units (oven, hotplate, refrigerator, dish washer, washing machine, dryer, fans, etc.), one could assume that the regression model derived for this accommodation provider might be reflective of a model that can be applied to other condominium complexes in the Gold Coast region (Warnken 2000).

In all of the seven cases that provided sufficient data to include mean monthly air temperatures in the regression analysis, this variable was found to explain some of the variation in monthly electricity consumption data. Based on advice provided by hotel engineers, the positive relationships between electricity and temperature for hotels were considered to be the result of running centralised air conditioning systems. These systems are 
running throughout the year, but have to be run at much higher loads during the hot and humid summer months. ${ }^{8}$

An inverse relationship between air temperature and electricity consumption was found for the only condominium complex that provided suitable data. It was reasoned that the absence of a centralised air conditioning system and increased use of self-standing heaters and hot water during cold periods were the main reasons for this particular observation.

Statistically significant positive relationships were found between monthly gas consumption and occupancy levels in 9 out of 11 analyses conducted. In most cases, these accommodation providers used gas for their hot water systems. Increased occupancy will not only increase the consumption of hot water in guest rooms, but also in laundry areas.

In five regression equations formulated, three reveal statistically significant negative relationships between monthly gas consumption and mean monthly temperature. Again, this can be explained by the use of gas for hot water systems. As temperatures rise there is likely to be less demand for hot water.

Overall, these results indicate that energy consumption is influenced to varying degrees by factors such as temperature and occupancy levels in different enterprises. The degree of influence is likely to be affected by variations in accommodation provider factors such as building style, level of insulation, technical standards, services and facilities provided, and type of hot water and air conditioning systems. Although these factors can frequently be relatively similar across accommodation providers within the same accommodation category, they can vary significantly across accommodation categories. To complicate matters further, new marketing strategies offer products in two or more of these categories. For example several resorts were noted to be marketing serviced rooms as well as self-contained

\footnotetext{
${ }^{8}$ It should be noted that data for this study was conducted in a tropical and sub-tropical region, where summer temperatures are relatively hot and winter temperatures relatively mild. If a similar study were to be conducted in a region that is subjected to more extreme winter temperatures, consideration could be given to calculating a "deviation from temperate" measure of temperature. When the "deviation
} 
apartments. As a consequence, energy consumption is likely to differ between different types of accommodation offered by one resort business. This suggests that for any particular accommodation category, energy relationships would have to be appraised from a wide range of businesses.

\section{The three sector-wide energy consumption accounting methods revisited}

\section{The Floor Area Method}

The main advantage of this approach is that floor area is a standardised objective measure that is readily obtainable for most accommodation providers. An important facet of the Floor Area Method is that it provides an indication of the energy consumption performance of buildings constructed with different configurations and insulation specifications. The method does have limitations, however. Firstly, it is not ideal for drawing environmental performance comparisons between different categories of accommodation, as different accommodation categories are characterised by different building shell specifications. Secondly, this method does not incorporate external factors that could affect the environmental performance of an accommodation provider over time.

The limitations of the approach signify it is difficult to isolate the extent to which different environmental management practices, or the installation of new technologies, have a "real" effect on environmental performance. For example, following installation of an energy efficient air conditioning system, an accommodation provider might observe a dramatic reduction in energy consumption. This reduction in energy use may not be due to the technical change alone, however. The reduced energy consumption might coincide with a period of reduced occupancy levels and unseasonally temperate weather conditions.

from temperate” is relatively high (i.e., hot or cold conditions) we would expect higher electricity consumption due to greater use of air conditioning or heating equipment. 
In addition, where accommodation providers provide mixed forms of accommodation, for example, resorts offering hotel style rooms as well as self-contained apartments, or caravan parks with cabin and campground accommodation, calculations of energy use in terms of floor area will be confounded. The respective energy intensities of the different accommodation styles, and the distribution of guests across the different forms of accommodation, will certainly affect energy consumption.

\section{The Multiple Regression Method}

This represents a more sophisticated method as it enables more that one determining variable to be included in the energy consumption model. The factors to be included in the model can be varied across the different accommodation categories. In addition, this method could include building shell factors in order to improve its predictive ability. It should be noted, however, that the greater the number of independent variables included in the model(s), the larger the sub-sample of businesses that will be needed in order to calculate relatively accurate parameter values.

In addition to its potential as a sector-wide accounting model, this method can also be used as a self-assessment tool for individual businesses. As noted earlier, Saxena and Modepalle (1994) used multiple regression analysis to develop such a tool. These researchers concluded that their model represented a feasible form of self-assessment that could highlight energy conservation opportunities.

An important consideration however, is that as older buildings are refurbished and new buildings constructed with improved energy conservation designs, regression models will have to be updated. In light of continuing rapid growth and change occurring in the accommodation sector, the regression models might need to be refined at fairly regular intervals, preferably annually, using different sub-sets of businesses.

An important factor uncovered by this study is the time consuming nature of collecting requisite data for applying the regression model approach. This problem was particularly 
apparent in the condominium sub-sector of the tourist accommodation industry. In what is a fragmented industry, the condominium sub-sector appears to be particularly fragmented relative to the hotel sub-sector. Fundamental to this problem is the fact that accommodation providers are not required to maintain energy consumption data. With an increasingly diversifying accommodation market, the work required to apply the multiple regression method is likely to become even more complex in the future.

\section{The Mandatory Reporting Method}

The principal advantage of this approach is that it ensures all businesses monitor their own environmental performance. This carries the corollary of heightening management's awareness of the environmental performance of their business. The modeling problems that arise due to the splintered nature of a fragmented industry underline the relative merit of mandatory reporting when dealing with heterogeneous business entities. Mandatory reporting appears to offer the greatest promise as a technique that achieves relatively accurate per capita measures of annual energy use and greenhouse gas emissions, for the entire tourist accommodation sector. Unfortunately, however, the fragmented nature of the industry signifies that mandatory reporting is unlikely to be readily accepted by all of the industry's sub-sectors, particularly those where small, family-run, operations predominate. Experience with reporting schemes implemented to collect sector-wide occupancy and revenue figures have already revealed the difficulty of collecting complete and reliable data (e.g. Greece: Leontidou, 1998).

Of the accommodation providers reviewed, it appears that the hotel sub-sector would be best placed to provide data required by a mandatory reporting scheme, as it has been found that many hotels already record energy consumption data. Operators with more complex management structures, such as condominiums, are likely to experience problems collecting and collating energy consumption data. As noted earlier, several different bodies might hold energy consumption data for one condominium complex (Figure 2). In cases where the Body Corporate service provider maintains common property accounts, and resident managers or 
apartment owners manage accounts for individual apartments, it will be difficult to collate data for an entire complex. On the other hand, data collection would be relatively straightforward for condominiums that purchase energy through the contestable consumption market. The separation of energy consumption between holiday-makers and permanent residents is likely to be difficult and could be a source of considerable measurement error. In such cases, special algorithms based on findings in other condominiums would have to be developed.

Despite these issues, the limited degree to which energy consumption data is recorded by small accommodation providers underlines the relative potential of the mandatory reporting method. Unless enterprises can identify gains for themselves in conducting in-house energy consumption audits mandatory reporting appears to be the most pragmatic approach of pursuing sector-wide energy consumption accounting in a fragmented industry.

\section{Conclusion and discussion}

Findings made in this study suggest that in-house energy consumption accounting for small to medium size businesses in the Australian accommodation sector are the exception rather than the rule. Following a review of the floor area, multiple regression and mandatory reporting methods of sector wide energy consumption accounting in the tourism industry, it appears that the mandatory reporting method offers the greatest potential. Not only does it appear to have the greatest promise in terms of facilitating data accuracy, it would encourage individual businesses to monitor their own environmental performance. Further, this method saves costs associated with employing independent auditors because it does not require direct collection of data from individual businesses. It does, however, signify an increased administrative burden for the accommodation providers.

An argument can also be made for using a combination of methods rather than placing complete reliance on a single approach. This can be seen as a strategy to counter factors 
detracting from an accurate gauge of sector-wide environmental performance. There are three arguments that support a multi-method approach.

Firstly, sector-wide environmental accounting is bound to be hampered by the reluctance of many businesses to record and release energy consumption data. Indeed, Mortimer et al. (1999) have commented on the difficulty of obtaining reliable data for energy use in nondomestic buildings. While it is understandable that dollar figures for electricity consumption are often considered “confidential information”, given their direct relationship with operating costs and profit, kWh or MJ figures on the other hand, are relatively neutral. Thus, mandatory reporting should be institutionalised, so that businesses are required to provide energy consumption data along with standard economic performance indicators, to central statistical agencies such as the $A B S$.

Secondly, results from the regression analyses indicated that temperature changes affect energy consumption. This implies that energy consumption and weather data should be collected for a number of years, in order to develop models that can incorporate the impact of unusual weather patterns. Large sample data sets would enable the development of more accurate models to account for unusual climatic conditions and even special economic and socio-cultural events that impact upon occupancy levels. Indeed, more extreme and erratic weather patterns have been predicted for the future (IPCC, 2001). In light of this, it would be unwise to ignore the effects of climate, or establish a quantified parameter for sector-wide energy consumption simply on the basis of twelve months' data. In addition, data collection should encompass categorical variables reflective of different types of building shell and design. ${ }^{9}$ As indicated by the data collected for this study, occupancy figures only have an effect on energy consumption in hotels with a compact design. Without such information, benchmarking exercises based on indiscriminate mandatory reporting could severely distort sub-sector figures. 
Thirdly, when investigating in-house environmental accounting, it was found that various methods and measures were used for recording energy figures, and data often covered different time periods. Unfortunately, inconsistent record keeping procedures are bound to hamper sector-wide energy consumption accounting initiatives. These inconsistencies signify that adjustments have to be made to raw data prior to collation and analysis. Accordingly, it is desirable that standardised electronic spreadsheets are developed for different types of accommodation. Not only would this increase data recording accuracy, it might encourage more energy consumption accounting at the individual business level. Examples of such spreadsheets have been developed by Good and Wirdzek (1999).

To facilitate effective "technology transfer" and encourage widespread uptake of these spreadsheets, it is important that their development is informed by representatives drawn from the full range of tourism accommodation sub-sectors noted in this study. In particular, consultations should be made with those who will be responsible for recording data, such as engineering and maintenance staff. In the case of the condominium sector, responsibility for recording energy consumption figures for entire complexes could be given to the body corporate service provider, who is responsible for other day-to-day administrative issues. In instances where individual unit owners hold energy bills for their own apartments, they could be required to submit energy consumption figures to the body corporate service provider.

It is obviously desirable that standardised spreadsheets are user-friendly and structured simply. Preferably, they should be designed to meet the criteria of international accreditation schemes such as ISO 14001 and Green Globe 21. Indeed, if operators can rely on easy to use data entry programs, they may be inclined to participate in national or international accreditation programs, which in turn will encourage incorporation of other aspects of environmental management in their day-to-day operations.

\footnotetext{
${ }^{9}$ Alternatively, the accommodation sector could be sub-divided with different regression models developed for different building types.
} 
Due to its continuing rapid growth and fragmented nature, this study has considered sector-wide energy consumption accounting in the context of the tourism industry. Despite this single industry focus, three recommendations offered appear generally applicable to any industry where energy consumption accounting is warranted. These recommendations are:

1) Industry sector environmental resource consumption and waste production data represent information that should be made publicly available.

2) Resource consumption and waste production figures should be collected over several years in order to enable the development of accurate models that capture the factors driving energy consumption.

3) Standardised spreadsheets should be developed for industrial sub-sectors to assist, facilitate and encourage the recording of business level achievements with respect to various dimensions of environmental performance.

If countries wish to seriously address their obligations under environmental treaties such as the Kyoto Protocol, then in-house environmental accounting and mandatory reporting of figures to a central agency, must be introduced for all key sectors of economic activity. 


\section{References}

Aulbach, R., 1988. Energy and Water Resource Management, ( $2^{\text {nd }}$ ed.). The Educational Institute of the American Hotel and Motel Association, East Lansing, Michigan.

ABS, 1997. Tourist Accommodation, Queensland, 8635.3, June Quarter 1997. Australian Bureau of Statistics, Belconnen, ACT.

Becken, S., Frampton, C., Simmons, D., in press. Energy Consumption Patterns in the Accommodation Sector - the New Zealand Case. Ecol. Econ., submitted.

Bhat, V., 1998. Total Quality Environmental Management. An ISO 14000 Approach. Quorum Books, Westport, Connecticut.

Buckley, R., 1991. Perspectives in Environmental Management. Springer-Verlag, New York.

Deng, S., Burnett, J., 2000. A study of energy performance of hotel buildings in Hong Kong. Energy and Buildings 31, 7-12.

Diamantis, D., Westlake, J., 1997. Environmental Auditing: An Approach Towards Monitoring the Environmental Impacts in Tourism Destinations, with Reference to the Case of Molyvos. Progress in Tourism and Hospitality Research 3, 3-15.

Ding, P., Pigram, J., 1995. Environmental Audits: An emerging concept in sustainable tourism development. J. Tour. Studies 6, 2-10.

Ehrlich, P., Ehrlich, A., 1990. The Population Explosion. Hutchinson, London.

Epstein, M.J., Roy, M.J., 1997. Environmental Management to Improve Corporate Profitability. Journal of Cost Management, November/December, 26-35.

Fennell, D., 1999. Ecotourism. An introduction. Routledge, London.

Good, L., Wirdzek, P., 1999. Auditing to the Cutting Edge. Energy Engineering 96, 63-79.

Goodall, B., 1995. Environmental Auditing: a tool for assessing the environmental performance of tourism firms. The Geographical Journal 161, 29-37.

Guilding, C., Kirman, C., 1998. Environmental Accounting in the New Zealand Contacting Industry. Pacific Accounting Review. 10, 27-50. 
Halloran, A., Higgins, T., Miketa, G., 1994. Multimedia waste auditing in Hungary: A waste minimization feasibility study for a metal plating facility. Wat. Sce. Tech. 30, 233-241.

Hamblin, A., 1991. Sustainability: Physical and Biophysical Considerations for Australian Environments. Working Paper No. WP 19/89. Bureau of Rural Resources, Department of Primary Industries and Energy, Canberra.

IPCC (Intergovernmental Panel on Climate Change), 2001. Third Assessment Report of Working Group 1. IPCC, Geneva, Switzerland, 98 pp.

Leontidou, L., 1998. Greece: Hesitant policy and uneven tourism development in the 1990s. In A. Montanari and A.M. Williams (Eds.) European Tourism: Regions, Areas and Restructuring (pp. 101-123). Chichester: Wiley

Marsden, J., 1996. Energy and environmental accounting. Mgmt. Accounting, 74, 42.

McMichael, A., 1993. Planetary Overload: Global Environmental Change and the Health of the Human Species. Cambridge University Press, Cambridge.

Mortimer, N., Ashley, A., Elsayed, M., Kelly, M., Rix, J., 1999. Developing a database of energy use in the UK non-domestic building stock. Energy Policy 27, 451-468.

Odum, E., 1998. Ecological Vignettes. Ecological Approaches to Dealing with Human Predicaments. Harwood Academic Publishers, Sydney.

Saxena, U., Modepalle, R., 1994. Development of Self Assessment Tool For Energy Conservation. Energy Engineering 91, 57-65.

Schaltegger, S., Burritt R., 2000. Contemporary Environmental Accounting: Issues Concepts and Practice. Greenleaf Publishing Limited, Sheffield UK.

Sinclair-Desgagne, B., Gabel, H.L., 1997. Environmental Auditing in Management Systems and Public Policy. J. Env. Econ. Mgmt. 33, 331-346.

Szwilski, T., Begley, R., 1998. Update on ISO 14000 EMS: Application to the mining industry. Mining Engineering 50, 71-73.

UK CEED, 1998. An Assessment of the Environmental Impacts of Tourism in St Lucia. British Airways Environment Report 5/98. UK CEED, Cambridge.

Warnken, J., 2000. Tourism Infrastructure Audit, Gold Coast. Work-in-progress report series, Cooperative Research Centre for Sustainable Tourism, Gold Coast. 
WCED, 1987. Our Common Future. Oxford Univeristy Press, Oxford. 
Table 1: Field study data collection:

Overview of businesses and individuals contacted

\begin{tabular}{lccc}
\hline Accommodation type & $\begin{array}{c}\text { Number of } \\
\text { individuals } \\
\text { contacted }\end{array}$ & $\begin{array}{c}\text { Number of } \\
\text { positive } \\
\text { responses }\end{array}$ & $\begin{array}{c}\text { Number of businesses } \\
\text { providing suitable data }\end{array}$ \\
\hline Hotels & 18 & 11 & 11 \\
Motels & 20 & 1 & $0^{\mathrm{a}}$ \\
Condominiums & & & \\
$\quad$ Body Corporate officials & 18 & 5 & 5 \\
$\quad$ Resident Managers & 23 & 11 & $9^{\mathrm{c}}$ \\
$\quad$ Unit owners & $\underline{65}$ & $\underline{29}$ & $11^{\mathrm{d}}$ \\
$\quad$ Sub-total & 106 & \multicolumn{2}{c}{$13^{\mathrm{e}}$} \\
Eco-resorts & 16 & 9 & $5^{\mathrm{f}}$ \\
Caravan parks & 10 & 1 & $1^{\mathrm{g}}$ \\
Total & $\mathbf{1 7 0}$ & $\mathbf{6 7}$ & $\mathbf{5 5}$
\end{tabular}

a - Data provided by the single positive respondent was not suitable for regression analysis.

b - Three different levels of management were contacted in connection with condominium data collection.

c - Unit owner contact details provided by managers did not always result in data collection.

d - Some unit owners could not supply figures for a twelve month period, others provided energy consumption figures in dollar terms rather than $\mathrm{kWh}$.

e - There was some overlap across the management levels. For example, some Body Corporate service providers, resident managers and unit owners represented the same building. Accordingly, this figure represents the total number of condominiums and not the total number of people that provided suitable energy consumption data.

f - Four businesses were excluded due to small accommodation capacity.

g - Contact with one central management company yielded data for six publicly owned caravan parks. 
Table 2: Characteristics of in-house energy consumption accounting for tourism accommodation providers appraised

\begin{tabular}{|c|c|c|c|c|}
\hline \multirow{2}{*}{$\begin{array}{l}\text { Name of } \\
\text { enterprise }\end{array}$} & \multicolumn{4}{|c|}{ Nature of energy consumption accounting } \\
\hline & Elec & Gas & Record keeper & Comments \\
\hline GC $^{*}$ Hotel 1 & $\mathrm{Y}$ & $\mathrm{Y}$ & Eng./maint. dept. ${ }^{\mathrm{a}}$ & $\begin{array}{l}\text { Standardised spreadsheets. Energy audit } \\
\text { performed in } 2000 \text { by local energy supplier. }\end{array}$ \\
\hline GC Hotel 2 & $\mathrm{Y}$ & $\mathrm{Y}$ & Eng./maint. dept. & Participant in GCP. ${ }^{\mathrm{b}}$ \\
\hline GC Hotel 3 & $\mathrm{Y}$ & n.a. ${ }^{\mathrm{c}}$ & Eng./maint. dept. & _- \\
\hline GC Hotel 4 & Y & n.a. ${ }^{\mathrm{c}}$ & Eng./maint. dept. & - \\
\hline SC Hotel 1 & $\mathrm{Y}$ & $\mathrm{Y}$ & Eng./maint. dept. & $\begin{array}{l}\text { Standardised spreadsheets. Complete energy } \\
\text { audit undertaken internally. Participant in GCP. }\end{array}$ \\
\hline SC Hotel 2 & $\mathrm{Y}$ & $\mathrm{Y}$ & Accounting dept. & _ \\
\hline SC Hotel $3^{d}$ & $\mathrm{Y}$ & $\mathrm{Y}$ & Eng./maint. dept. & $\begin{array}{l}\text { Standardised spreadsheets. Participant in Green } \\
\text { Hoteliers competition and GCP. }\end{array}$ \\
\hline Cairns Hotel 1 & $\mathrm{Y}$ & $\mathrm{Y}$ & Eng./maint. dept. & _ \\
\hline Cairns Hotel 2 & $\mathrm{Y}$ & $\mathrm{Y}$ & Eng./maint. dept. & $\begin{array}{l}\text { Standardised spreadsheets. Complete energy audit } \\
\text { undertaken internally. Participant in GCP. }\end{array}$ \\
\hline Cairns Hotel 3 & $\mathrm{Y}$ & $\mathrm{Y}$ & Eng./maint. dept. & $\begin{array}{l}\text { Parent hotel chain conducts an internal audit } \\
\text { every } 12 \text { months. Participant in GCP. }\end{array}$ \\
\hline Cairns Hotel 4 & $\mathbf{y}$ & $\mathbf{y}$ & Eng./maint. dept. & Incomplete records. \\
\hline GC Eco 1 & $\mathbf{y}$ & $\mathbf{y}$ & Accounting dept. & $\begin{array}{l}\text { Eco-efficiency assessment undertaken in } \\
\text { conjunction with the EPA }{ }^{\mathrm{e}} \text {. Independent } \\
\text { environmental audit conducted by the University } \\
\text { of Queensland, Gatton - unpublished. }\end{array}$ \\
\hline GC Eco 2 & $\mathrm{Y}$ & n.a. ${ }^{f}$ & Eng./maint. dept. & $\begin{array}{l}\text { Centralised electronic Advanced Energy System - } \\
\text { continually monitors energy consumption } \\
\text { throughout the resort. }\end{array}$ \\
\hline GC Eco 3 & $y$ & $y$ & $\begin{array}{l}\text { Ecotourism } \\
\text { Manager }\end{array}$ & $\begin{array}{l}\text { Two independent environmental audits } \\
\text { undertaken by the University of Queensland, } \\
\text { Gatton - unpublished. }\end{array}$ \\
\hline Cairns Eco 1 & $y$ & $y$ & Eng./maint. dept. ${ }^{g}$ & Electricity records incomplete. \\
\hline Cairns Eco 2 & $y$ & $y$ & Resort Manager ${ }^{\mathrm{g}}$ & Electricity records incomplete. \\
\hline GC Caravans $1-6^{\mathrm{h}}$ & $\mathrm{Y}$ & $\mathrm{Y}$ & $\begin{array}{l}\text { Central } \\
\text { management co. }\end{array}$ & $\begin{array}{l}\text { Independent energy audits undertaken by local } \\
\text { energy supplier. }\end{array}$ \\
\hline
\end{tabular}

*GC denotes Gold Coast; SC denotes Sunshine Coast.

Y: electronic record-keeping; $y$ : manual record-keeping

a - Engineering/maintenance department.

b - Greenhouse Challenge Program, a Program developed by the Australian Greenhouse Office encouraging businesses to adopt measures to reduce greenhouse gas emissions.

c - Figures probably recorded but they were not provided.

d - Utility consumption recorded on a four monthly basis. All other enterprises recorded energy consumption on a monthly basis.

e - Environmental Protection Agency, Queensland

$\mathrm{f}$ - Resort uses gas powered generators; energy use is recorded as kWh of electricity consumed.

$\mathrm{g}$ - Local gas supplier provided figures for gas consumption because the enterprise did not record these in a form that was suitable for analysis.

$\mathrm{h}$ - Central management company oversees the operation of this group of caravan parks. 
Table 3: Regression results - factors affecting energy consumption

\begin{tabular}{|c|c|c|c|c|c|c|c|c|}
\hline \multirow[t]{2}{*}{ Enterprise } & \multicolumn{4}{|c|}{ Electricity } & \multicolumn{4}{|c|}{ Gas } \\
\hline & Оссир $^{\mathrm{e}}$ & Temp $^{f}$ & $R H 3^{g}$ & $n$ & Occup & Temp & RH 3 & $n$ \\
\hline GC $^{\text {a }}$ Hotel 1 & n.s. & *** & n.s. & 68 & ** & n.s. & n.s. & 61 \\
\hline GC Hotel 2 & * & ** & n.s. & 75 & ** & $x x x$ & - & 24 \\
\hline GC Hotel 3 & n.s. & $* *$ & n.s. & 55 & - & - & - & 0 \\
\hline GC Hotel 4 & $*$ & - & - & 12 & - & - & - & 0 \\
\hline SC $^{\mathrm{b}}$ Hotel 1 & n.s. & $* * *$ & - & 72 & $*$ & $x \times x$ & - & 72 \\
\hline SC Hotel 2 & n.s. & - & - & 12 & - & - & - & 0 \\
\hline Cairns Hotel 1 & n.s. & - & - & 12 & n.s. & - & - & 12 \\
\hline Cairns Hotel 2 & n.s. & $* * *$ & - & 24 & $* *$ & n.s. & - & 24 \\
\hline Cairns Hotel 3 & $* *$ & $* * *$ & n.s. & 36 & $* * *$ & $x x x$ & n.s. & 36 \\
\hline $\mathrm{GC} \mathrm{Eco}^{\mathrm{c}} 1$ & n.s. & - & - & 12 & - & - & - & 0 \\
\hline GC Eco 2 & $* * *$ & - & - & 12 & - & - & - & 0 \\
\hline GC Eco 3 & n.s. & - & - & 12 & - & - & - & 0 \\
\hline Cairns Eco 1 & - & - & - & 0 & - & - & - & 0 \\
\hline Cairns Eco 2 & - & - & - & 0 & - & - & - & 0 \\
\hline $\begin{array}{l}\text { GC condominium } 3^{\mathrm{d}} \text { : } \\
\text { all units } \& \text { common } \\
\text { property }\end{array}$ & n.s. & - & - & 12 & - & - & - & 0 \\
\hline $\begin{array}{l}\text { GC condominium 5: all } \\
\text { units in data collection }\end{array}$ & $* *$ & $x x$ & n.s. & 525 & - & - & - & 0 \\
\hline GC Caravan Park 1 & n.s. & - & - & 12 & n.s. & - & - & 0 \\
\hline GC Caravan Park 2 & n.s. & - & - & 12 & $* *$ & - & - & 0 \\
\hline GC Caravan Park 3 & $* *$ & - & - & 12 & ** & - & - & 0 \\
\hline GC Caravan Park 4 & n.s. & - & - & 12 & $*$ & - & - & 0 \\
\hline GC Caravan Park 5 & n.s. & - & - & 12 & $*$ & - & - & 0 \\
\hline GC Caravan Park 6 & n.s. & - & - & 12 & - & - & - & 0 \\
\hline \multicolumn{9}{|l|}{$\mathrm{a}-$ Gold Coast } \\
\hline \multicolumn{9}{|l|}{ b - Sunshine Coast } \\
\hline \multicolumn{9}{|l|}{ c - Eco-resorts } \\
\hline \multicolumn{9}{|c|}{$\begin{array}{l}\mathrm{d} \text { - Occupancy figures used for this regression model covered the entire complex, all holiday and } \\
\text { permanent resident units. An assumption was made that occupancy in permanent resident units was } \\
\text { always } 100 \% \text {. }\end{array}$} \\
\hline \multicolumn{9}{|c|}{ e - Monthly occupancy } \\
\hline \multicolumn{9}{|c|}{$\mathrm{f}$ - Mean monthly air temperature } \\
\hline \multicolumn{9}{|c|}{ g- Relative humidity at 3pm, limited figures available for the Sunshine Coast. } \\
\hline \multicolumn{9}{|c|}{ Positive relationship: $*<0.05, * *<0.01, * * *<0.001$} \\
\hline Negative relationshi & $x x<0.01$ & $x \times x<0$. & & -signi & th result: & & & \\
\hline
\end{tabular}


Figure 1a and 1b: Management structures for different accommodation providers in Queensland, Australia 
Figure 2: Different arrangements for electricity purchase and payment in the deregulated energy market, Queensland, Australia

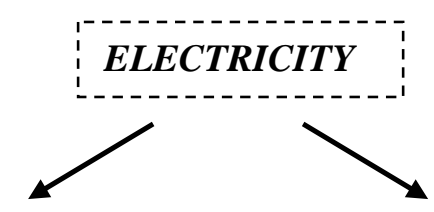

Contestable consumption

market<smiles>CCOC</smiles>

Body Corporate service provider manages common property accounts and accounts for individual apartments

On tariff with local network provider

Body Corporate service provider manages common property accounts

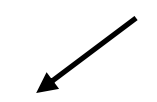

Apartment Owners manage their own accounts

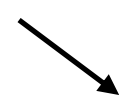

Resident Managers manage apartment accounts on behalf of owners 